Thus take the broggerite found in the preCambrian rocks at Moss, Norway. The lead in this mineral has an atomic weight of 206.06 as determined by Hönigschmied and Fräulein St. Horovitz. The ratio of lead to uranium is $1: 3$. Taking the lead as all produced by uranium at the rate above given, we get an age of 925 million years. Some minerals from other archæan rocks in Norway give a rather longer age.

In other cases there is some complication, awing to the fact that thorium is associated with uranium in the mineral and that it, too, produces helium and an isotope of lead of atomic weight probably 208 exactly, about one unit higher than common lead.

In a third class of cases the uranium mineral. pitchblende, occurs in a metalliferous vein, and the lead isotope produced in the mineral is diluted with common kead which entered into its original composition.

These various complications introduce a certain amount of difficulty and even ambiguity into the interpretation. A full discussion cannot be given on an occasion like the present, but the complications cannot, I think, be considered to modify the broad result.

A determination of the amount of helium in minerals gives an alternative method of estimating geological age; but helium, unlike lead, is liable to leak away, hence the estimate gives a minimum only. I have found in this way ages which, speaking generally, are about one-third of the values which estimations of lead have given, and are, therefore, generally confirmatory, having regard to leakage of helium.

The helium method is applicable in some cases to materials found in the younger formations, and proves that the ages even of these are to be reckoned in millions of years. Thus the helium in an Eocene iron ore indicated thirty million years at least.

Returning now to the estimation of lead, H. N. Russell has recently applied this line of reasoning to the earth's crust as a whole. He takes the uranium in the earth as $7 \times 10^{-6}$ of the whole, and the lead as $22 \times 10^{-6}$ of the whole. It is necessary to remark that we do not know very definitely whether the lead distributed in the rocks in small proportion and very difficult of extraction is the same mixture of isotope as the lead of mineral veins. We call the latter "common lead," but nearly all the lead in the earth's crust is of the former kind.

Even if we did know that "rock lead" were the same as "vein lead," we should still not be in a position to say what fraction of it was uranium-lead, as we do not know whether an isotope having an atomic weight 207 exists. If it does, obviously the problem how much uraniumlead (atomic weight 206) and how much thoriumlead (atomic weight 208) exists in common lead (atomic weight 207 ) becomes indeterminate in the absence of further data. An analysis of lead by positive rays will probably soon become feasible, and with a determination of the atomic weight of "rock lead" will do much to clear up the matter.

If all the lead were uranium-lead, and had been generated since formation of the earth's crust, the time required would be $I I \times 10^{9}$ years. This is certainly too great. Allowing for the production of some of the lead from thorium, Russell finds a period of $8 \times 10^{9}$ years as the upper limit. This is about six times the age indicated by the oldest individual radio-active minerals that have been examined.

I have now traversed that part of our subject of which I feel competent to speak. 'The upshot is that radio-active methods of research indicate a moderate multiple of 1000 million years as the duration of the earth's crust as suitable for the habitation of living beings, and that no other considerations from the side of pure physics or astronomy afford any definite presumption against this estimate.

The arguments from geology and biology I must leave to our colleagues from other sections. May I venture to say that I for one consider the topics with which they will deal as not less interesting and important than those which it has been my privilege to try to lay before you.

\title{
By Prof. W. J. Sollas, F.R.S.
}

$\mathrm{H}$ UXLEY once sagely remarked that the zoologist must take his time from the geological clock. The geologist is thus charged with a great responsibility which he would willingly share with the physicist and astronomer. One of the earliest attempts to determine the age of the earth by purely geological means was made by the late Dr. Samuel Haughton, who based his calculations on the rate of deposition of sediment supposed to be evenly distributed over the whole floor of the ocean. This led to the conclusion that the time which must have elapsed since the first appearance of the dry land is of the same order of magnitude as that now presented for our consideration by Lord Rayleigh.

Soon, however, it was discovered, as a result of exploration by the Challenger, that deposition is limited to a comparatively narrow belt bordering the continents-a limitation due to several causes, chief among them the fact that sediment sinks much more rapidly in salt water than fresh. On taking account of this factor Haughton's period was reduced to about roo million years. At the same time a new method was devised by Prof. Joly which depends on the rate at which sodium is supplied to the sea, and this led to a similar result.

Antecedent to these attempts, another method, based on the rate at which the earth is losing heat, had been employed by Lord Kelvin, and this gave at first an estimate concordant with the preceding-i.e. 100 million years. Later, how-

NO. 27 I3, VOL. I०8] 
ever, this allowance was reduced to forty, or preferably to twenty, millions, and by the uncompromising Prof. Tait to ten millions.

These estimates proved very embarrassing to the geologist, who found it impossible to compress the events of the earth's history into so restricted an interval without unduly "hurrying up the phenomena." Lord Kelvin, however, was inflexible, and impressively asserted that he could conceive of no escape from his conclusions.

With the discovery of radioactive elements the inconceivable happened, and Lord Rayleigh was amongst the first to perceive that the rate of disintegration of uranium might be used to provide the geologist with a trustworthy timekeeper. By his experiments and reasoning he not only enlarged our views on the duration of geological time, but also opened the way to other methods of investigation which in the hands of Prof. Joly and Dr. Holmes have yielded concordant results.

The age of the earth was thus increased from a mere score of millions to a thousand millions and more, and the geologist who had before been bankrupt in time now found himself suddenly transformed into a capitalist with more millions in the bank than he knew how to dispose of.

The consequences have been far-reaching; already some geologists, thus newly enriched, chief among them the brilliant Barrell, whose loss we still deplore, have begun to rebuild their science on a new and magnificent scale, while more cautious people, like myself, too cautious, perhaps, are anxious first of all to make sure that the new clock is not as much too fast as Lord Kelvin's was too slow. Lord Rayleigh does not regard this as inconceivable, but as unlikely. Prof. Joly, on the other hand, can not only conceive a source of error, but has obtained evidence which seems to show where it lies. This is furnished by a study of the well-known pleochroic haloes which surround minute uranium- or thorium-bearing crystals included in the black mica of granite. By a very elegant method of investigation he shows that these furnish estimates of geological time of the same order as those established by Lord Rayleigh and Dr. Holmes; but he does not stop there; he goes further. The haloes consist of a number (seven) of concentric rings due to the bombardment of the mica by the $\alpha$-rays which are emitted by the uranium or the thorium, as the case may be, and their products of disintegration. The outermost of these rings is due to radium $\mathrm{C}$, the innermost to uranium or thorium. From data provided by experiment it is possible to calculate the dimensions of the rings, and in the haloes due to thorium the length of the radii obtained by direct measurement agrees very precisely with that obtained by calculation, and this agreement holds, not for some of the rings only, but for all. A similar agreement is found for the rings of the uranium haloes with the remarkable exception of the innermost two, due to uranium and its immediate product, ionium. These are larger than NO. 27 I3, VOL. IO8] they should be; in fact, the length of the radius of the uranium ring as actually observed is onesixth longer than that predicted by calculation. This shows that when the haloes began to be formed-i.e. in Caledonian times-the range of the $\alpha$-rays emitted by the uranium-bearing crystal was greater than it is now, and hence probably that a metope of uranium then existed with possibly very different properties from the uranium now known to us.

If Prof. Joly's conclusions are sound, it is clear that the uranium clock has not been keeping uniform time, and the change of rate in the disintegration of uranium is as much in question as the age of the earth. The problem is a physical one, and geologists must leave it in the hands of the physicists while anxiously awaiting its solution.

It would not be fair to end here without admitting, what Prof. J. W. Gregory's remarks will sufficiently reveal, that geologists are not an undivided family. There are some who welcome the expansive vistas now opened to their view, and Barrell has already attempted to readjust the geological perspective. He pointed out how the calculations of the earth's age, based on the thickness of deposits and the existing rate of deposition, as well as those based on the amount of sodium in the ocean, may be vitiated by a too servile interpretation of the doctrine of uniformity. The rate of disintegration of uranium may have changed, but so may the rate of denudation and deposition; so far from being constant, it may have increased with the progress of time, so that a foot of sediment which in the Pleistocene epoch accumulated, according to Barrell, in the course of 375 years would have required no less than 3700 years for its formation in the early days of the Palæozoic era. Thus at a period when the earth was more highly charged with energy its activities were diminished. We must no longer picture a time when the earth was "young and wantoned in her prime," but must suppose that she has exchanged the passive indolence of youth for the fiery activity of old age.

In support of his views Barrell pointed out that the continents of the present day are more elevated as a whole than they were during a great part of geological time, and that their interior is not flooded to so great an extent by continental seas. It is doubtful, however, whether this would greatly affect those estimates which have been based on the maximum thickness of sedimentary deposits, for this is only to be found in the foredeeps which lay in front of mountainous lands and lands now vanished from our sight.

Barrell also laid great stress on the occurrence of gaps in the stratified series, unconformities, disconformities, and still smaller lacunæ which he termed diastemata. Of the important bearing which unconformities must have upon this discussion there can be no doubt. They were not overlooked in arriving at an estimate of roo million years. The disconformities are only now beginning to receive the attention to which their 
importance entitles them. In our own country we are familiar with them in the Jurassic system, but with us this system is far from attaining its maximum thickness-it does not exceed $8000 \mathrm{ft}$. while elsewhere it is represented by deposits of $20,000 \mathrm{ft}$. or more. The presence of numerous and well-marked disconformities in the British Jurassic rocks is, therefore, not surprising; whether they have the same importance in areas of maximum deposition has yet to be shown.

The estimates based on the rate at which sodium is supplied by rivers to the sea are in remarkable agreement with those derived from a study of stratified deposits. The objection that most of the sodium in river water has been directly derived from the sea was raised long ago by $\mathrm{Mr}$. Ackroyd, of Halifax, but was shown on investigation to be invalid.

No importance can be attached to the salinity of the sea in the early part of the Cambrian epoch, for as much time or more had elapsed before that period as followed after it. The first era of geological time, which has been called the Protæon, and the second, or Deuteræon, are of approximately equal length. From what we know of the behaviour of existing marine forms when exposed to brackish water conditions we have no reason to suppose that the Cambrian faunas could not

\section{By Prof. J. W. Gregory, F.R.S.}

THE claim that geological time must be restricted within a score, or a few score, million years was regarded by most geologists with incredulity, since a score million years was of little more use to geology than the seven days of the Pentateuch. Now that physical evidence allows the age of the earth to be counted by the thousand million years the problem is of less concern to the geologist, except from the hope that the uranium-lead ratio may fix geological dates in years, and from the interest of reconciling the conflicting results of the different methods.

The geological estimates to which most weight has been attached are based on the saltness of the sea. The salinity. argument has been widely accepted as sound in principle; the estimates varied from 70 to I 50 million years, and some intermediate length was regarded as inevitable. Allowances were made for various factors; but they added only a few per cent. to the total, and did not multiply it by ten or more.

The validity of the salinity argument may be tested by two checks - the supply of chlorine, and the denudation required to account for the amount of sodium; and as shown by Dr. A. Holmes, each of these indicates a much longer period than the sodium.

The supply of chlorine in igneous rocks is quite inadequate to convert their sodium into chloride. Most of the sodium chloride in river water is probably marine in origin, and only the sodium in the bicarbonate and sulphate is a fresh addition have flourished in a sea only half as salt as the existing ocean.

Juvenile waters, often rich in sodium and chlorine, no doubt contribute to the contents of existing rivers, but if, as seems likely, they furnished a larger contribution in past times, the effect would be to shorten instead of lengthening Prof. Joly's estimate.

Finally, it may be pointed out that in the only instance where estimates based on the thickness of deposits can be brought into comparison with a stricter determination of time the former have been found in excess. This stricter determination is due to Baron de Geer, who, by counting the number of annual layers of sediment left behind by the great ice-sheet in its retreat, found for the duration of post-glacial time a period of 12,000 years, and thus shorter by several thousand years than those arrived at from a study of the post-glacial deltas in the Swiss lakes.

Geologists are not greatly concerned over the period which physicists may concede to them; they do not much care whether it is long or-in moderation-short, but they do desire to make reasonably certain that it is one which they can safely trust before committing themselves to the reconstruction of their science, should that prove to be necessary.

to the sea. On this ground the salinity estimate should be approximately doubled. Again, to obtain all the sodium in the sea from igneous rocks would involve the denudation of improbable volumes of them, and, at the rate usually accepted, the age of the earth should be multiplied threeor four-fold.

The fundamental objections to the salinity argument are against (I) its assumption that the sea was originally fresh, which palæontological evidence renders improbable: the oldest fauna, the Cambrian, has the characteristics of a marine fauna, and the contrast between the freshwater and marine faunas was as sharp in Palæozoic times as it is to-day; (2). its omission to allow for the large supplies of sodium chloride raised from beneath the earth's surface by magmatic waters; (3) its assumption of uniform denudation. The earth has probably undergone deformations that led to alternate periods of quick and slow crustal movement; during the times of repose the surface would have been planed down and rivers would have become sluggish and denudation slow. As the earth is now under the influence of a time of quick movement, denudation is faster than the average. A multiplication of the earth's age five-fold for this difference would not be excessive.

During quick crustal movement volcanic action would be more powerful, the discharge of hydrochloric acid and sodium in hot springs would be increased; and as denudation is now acting on land in which sodium chloride has been produced in unusual quantities by volcanic action the esti-

NO. 27 I3, VOL. IO8] 